\title{
3D Printing Filaments Prepared from Modified Poly(Lactic Acid)/ Teak Wood Flour Composites: An Investigation on the Particle Size Effects and Silane Coupling Agent Compatibilisation
}

\author{
Nawadon Petchwattana, ${ }^{1 *}$ Wasinee Channuan, ${ }^{1}$ Phisut Naknaen ${ }^{2}$ and Borwon Narupai ${ }^{3}$ \\ ${ }^{1}$ Division of Polymer Materials Technology, Faculty of Agricultural Product Innovation \\ and Technology, Srinakharinwirot University, Ongkharak, \\ Nakhon Nayok 26120, Thailand \\ ${ }^{2}$ Division of Food Science and Nutrition, Faculty of Agricultural Product Innovation and \\ Technology, Srinakharinwirot University, Ongkharak, Nakhon Nayok 26120, Thailand \\ ${ }^{3}$ Expert Center of Innovative Materials, Thailand Institute of Scientific and Technological \\ Research, Pathumthani 12120, Thailand
}

*Corresponding author: nawadon@g.swu.ac.th

Published online: 25 August 2019

To cite this article: Petchwattana, N. et al. (2019). 3D printing filaments prepared from modified poly(lactic acid)/teak wood flour composites: An investigation on the particle size effects and silane coupling agent compatibilisation. J. Phys. Sci., 30(2), 169-188, https://doi.org/10.21315/jps2019.30.2.10

To link to this article: https://doi.org/10.21315/jps2019.30.2.10

\begin{abstract}
This study aims to produce the poly(lactic acid) (PLA)/teak wood composite filament for $3 D$ printing application. Prior to the production of the wood plastic composite (WPC) filaments, PLA was modified to remedy the problem of brittleness and low-melt viscosity by core-shell rubber (CSR) particles and acrylic processing aid (APA). Two different particle sizes of teak wood flour (WF) were added to the modified-PLA (mPLA). Silane coupling agent was further added to improve the interfacial adhesion between the hydrophilic WF and hydrophobic mPLA matrix. Experimental results indicated that all formulations could be fabricated as $3 D$ printing filaments. However, the filaments were successfully printed only for the mPLA with $74 \mu \mathrm{m} W F$. For $125 \mu \mathrm{m}$, the printer nozzle was clogged up with the agglomerated WF. WPC filaments had higher water uptake than those mPLA and neat PLA, but it significantly decreased with the silane compatibilisation. SEM result also confirmed the improvement of the interfacial bonding between $M P L A$ and WF, which facilitated better fibre-matrix stress transfer and improved the overall mechanical strength.
\end{abstract}

Keywords: 3D printing, PLA filament, wood plastic composites, biodegradable polymers, fused deposition modelling 


\section{INTRODUCTION}

Three-dimensional (3D) printing is a rapidly expanding technology. It has become popular in recent years due to its extension to the household level, with affordable price. ${ }^{1,2}$ Moreover, 3D printing technology provides much more simple processing method compared with other thermoplastic processes. Although there are many 3D printing methods, the fused deposition modelling (FDM) is the most widely known and used. The steps involved in FDM working procedure are as follows: (1) designing a product by using 3D design software application; (2) sending the designed file to the 3D printer; (3) extruding the filament through the die; (4) moltening of filament stacks into layers; and (5) removing the product from the printer. ${ }^{3-5}$ Even though there are many polymer-based filaments used in 3D printer such as acrylonitrile butadiene styrene terpolymer (ABS), polylactic acid (PLA), and polycarbonate (PC) or other thermosetting plastics, the most common one is PLA which is produced from renewable resources and biodegradable. ${ }^{6,7}$ However, in the past five years, most literature works reported the processing techniques and printability of pure polymers which limited the polymer of 3D printed products in other textural appearances.

In recent years, there are only few literature works that reported the use of 3D printing with the wood/polymer composites (WPC). The main factor influencing the printability of the WPC filament is the wood content, particle/fibre geometry and the particle size. Tao et al. produced the PLA filament with the Aspen wood particles of $14 \mu \mathrm{m} .{ }^{3}$ They concluded that WPC filament was possibly printed by the FDM process. Another work focused on the mechanical properties of the WPC filaments. The authors concluded that the mechanical properties of WPC FDM directly depended on the fibre anisotropy. The 3D-printed products were found to have relatively high porosity, which directly decreased the mechanical strength and increased the water absorption and swelling rates. ${ }^{5}$

Adding the hydrophilic wood/natural fibres to the hydrophobic polymer is naturally incompatible. This was found to: (1) reduce the fibre-matrix stress transfer and lower the mechanical strength of WPC; and (2) increase the water absorption rate and dimensional instability of WPC. ${ }^{8,9}$ To improve the interfacial bonding between wood fibres and polymer matrices, numerous compatibilisers had been applied. ${ }^{8-12}$ In poly(vinyl chloride) (PVC)/wood composites, the significant improvement of the interfacial adhesion between PVC and WF was observed when aminosilane was added. Moreover, the water absorption of the treated composites was lower than that of the unmodified WPC. ${ }^{8}$ Utilisation of maleic anhydride (MA) grafted PLA increased the strength of the PLA/wood composites, while the use of silane 
coupling agent was found to improve the mechanical properties and reduce the water absorption as well. ${ }^{10,11}$

To extend these studies, the current research focuses on producing PLA/ WF composites filaments with different particle sizes of teak WF of $74 \mu \mathrm{m}$ and $125 \mu \mathrm{m}$. Further modification was carried out by adding the $\gamma$-aminopropyltrimethoxy silane to promote the interfacial adhesion and reduce the water absorption rate of the filaments. The printability test was also carried out and compared with those of commercial PLA filament.

\section{EXPERIMENTAL}

\subsection{Raw Materials}

3D printing monofilament grade of PLA (Ingeo ${ }^{\mathrm{TM}}$ Biopolymer 4043D, NatureWorks LLC) was employed as a polymer matrix. Due to the brittle nature and low melt viscosity of PLA, an acrylic processing aid (APA) (PARALOIDTM BPMS-250, The Dow Chemical Company) was added as a melt-strength enhancer for filament extrusion. An acrylic core-shell rubber (CSR) (PARALOID ${ }^{\mathrm{TM}}$ BPM515) was added as an impact modifier. The CSR structure is composed of the acrylic rubber core and poly(methyl methacrylate) (PMMA) shell with the glass transition temperature of $-40^{\circ} \mathrm{C}$ and $105^{\circ} \mathrm{C}$, respectively. ${ }^{13}$ Typical properties of PLA, APA and CSR are clearly listed in Table $1 .{ }^{13}$ Prior to producing the wood plastic composite filaments, PLA was modified by both CSR and APA to obtain modified PLA (mPLA). Teak WF (Tectona grandis) was obtained as waste from Mow Heng Li Sawmill, Ayutthaya, Thailand. It was then prepared by grinding and sieving to the top cut size of $74 \mu \mathrm{m}$ (200 mesh) and $125 \mu \mathrm{m}$ (120 mesh). Their aspect ratios were 0.57 and 0.58 , respectively. To improve the compatibility between mPLA and teak WF, $\gamma$-aminopropyl trimethoxy silane was added as a coupling agent. The blend formulations of PLA, APA, CSR, silane coupling agent and WF are shown in Table 2. Some mechanical, thermal and physical properties were performed on the $3 \mathrm{D}$ filaments and compared with that of commercial PLA filament (MakerBot).

Table 1: Typical properties of PLA, APA and CSR.

\begin{tabular}{llll}
\hline Designation & PLA 4043D & APA & CSR \\
\hline Physical appearance & Translucent pellet & White powder & White powder \\
Specific gravity & 1.24 & 1.19 & N/A \\
Bulk density & N/A & $0.4-0.52 \mathrm{~g} \mathrm{~cm}^{-3}$ & $0.48-0.56 \mathrm{~g} \mathrm{~cm}^{-3}$ \\
\hline
\end{tabular}


Table 1: (continued)

\begin{tabular}{llll}
\hline Designation & PLA $4043 \mathrm{D}$ & APA & CSR \\
\hline $\begin{array}{l}\text { Melting point } \\
\text { Water solubility }\end{array}$ & $145^{\circ} \mathrm{C}-160^{\circ} \mathrm{C}$ & $132^{\circ} \mathrm{C}-149^{\circ} \mathrm{C}$ & N/A \\
$\begin{array}{l}\text { Melt flow index at } \\
210^{\circ} \mathrm{C}\end{array}$ & $10.5 \mathrm{~g} 10 \mathrm{~min}^{-1}$ & Insoluble & Insoluble \\
\hline
\end{tabular}

N/A: no data available

\subsection{Preparation of PLA Composite Filaments and 3D Printed Products}

After dry-blending each formulation shown in Table 2, all of the blend compositions were then melt-mixed by using a twin screw extruder (Charoen Tut, E101) at a screw speed of $50 \mathrm{rpm}$. The temperature profile along the barrel from zone 1 to zone 5 was $160^{\circ} \mathrm{C} / 170^{\circ} \mathrm{C} / 180^{\circ} \mathrm{C} / 190^{\circ} \mathrm{C} / 190^{\circ} \mathrm{C}$ respectively. The melt-blended formulations were extruded and obtained WPC filaments with the diameter of $1.75 \mathrm{~mm}$ (Figure 1), for testing and characterisations.

Table 2: Formulation of PLA, APA, CSR and WF.

\begin{tabular}{lcccccc}
\hline & \multicolumn{6}{c}{ Material compositions (wt\%) } \\
\cline { 2 - 6 } Formulation code & PLA & CSR & APA & Silane & \multicolumn{3}{c}{ WF } \\
\cline { 2 - 6 } & 100 & 0 & 0 & 0 & 0 & 0 \\
PLA & 95 & 2.5 & 2.5 & 0 & 0 & 0 \\
mPLA & 94 & 2.5 & 2.5 & 0 & 1 & 0 \\
mPW74-1 & 92 & 2.5 & 2.5 & 0 & 3 & 0 \\
mPW74-3 & 90 & 2.5 & 2.5 & 0 & 5 & 0 \\
mPW74-5 & 94 & 2.5 & 2.5 & 0 & 0 & 1 \\
mPW125-1 & 92 & 2.5 & 2.5 & 0 & 0 & 3 \\
mPW125-3 & 90 & 2.5 & 2.5 & 0 & 0 & 5 \\
mPW125-5 & 85 & 2.5 & 2.5 & 5 & 5 & 0 \\
mPW74-5S & 85 & 2.5 & 2.5 & 5 & 0 & 5 \\
mPW125-5S & - & - & - & - & - & - \\
Commercial filament & & & & & 0 & 0 \\
\hline
\end{tabular}




\subsection{Testing and Characterisations}

\subsubsection{Testing of PLA/wood composite filaments}

The tensile test of WPC single-filament was conducted according to ASTM D3822 by using a Universal Testing Machine (INSTRON, 5567). The reported values were averaged from ten test specimens. The microscopic observation of the filaments was conducted by using an optical microscope (Nikon, Eclipse 50i Pol). Thermal transitions of the PLA, mPLA, PLA/WF and the commercial PLA filament were observed by using a differential scanning calorimeter (DSC) (Perkin Elmer, DSC6000) under nitrogen atmosphere. Initially, the test samples were nonisothermally heated from $0^{\circ} \mathrm{C}$ to $200^{\circ} \mathrm{C}$ and then isothermally held at $200^{\circ} \mathrm{C}$ for $5 \mathrm{~min}$ to remove thermal history at the ramp rate of $10^{\circ} \mathrm{C} \mathrm{min}^{-1}$. After that, they were non-isothermally cooled down to $0^{\circ} \mathrm{C}$ at the identical ramp rate and then isothermally held at $0^{\circ} \mathrm{C}$ for $5 \mathrm{~min}$. Finally, they were re-heated to $200^{\circ} \mathrm{C}$ at the heating rate of $10^{\circ} \mathrm{C} \mathrm{min}^{-1}$ to obtain the second heating thermogram data. The melt flow index (MFI) was conducted by using a melt flow indexer (Charoen Tut model MFR1) following the method described in ASTM D 1238.

The transition temperatures, namely glass transition temperature $\left(T_{g}\right)$, crystallisation temperature $\left(T_{c}\right)$ and melting temperature $\left(T_{m}\right)$ were estimated from the DSC heating curve. To calculate the degree of crystallinity $\left(X_{c}\right)$, the crystallisation enthalpy $\left(\Delta H_{c}\right)$ and the melting enthalpy $\left(\Delta H_{m}\right)$ were observed and the area under curve was calculated. The $X_{c}$ value was estimated by Equation 1. The sample weight applied on each DSC test was $10 \mathrm{mg}$ :

$$
X_{c}(\%)=100 \times \frac{\Delta H_{m}-\Delta H_{c}}{\Delta H_{f} \times X_{P L A}}
$$

where $X_{P L A}$ is the weight fraction of the PLA. $\Delta H_{f}$ is the heat of fusion, defined as the melting enthalpy of $100 \%$ crystalline PLA, which is $93 \mathrm{~J} \mathrm{~g}^{-1} \cdot{ }^{14-16}$

Chemical properties of the untreated and the silane-treated PLA/WF composites were analysed by using a Fourier transform infrared (FTIR, Nicolet is 5) spectrophotometer at wavenumber of $650-4000 \mathrm{~cm}^{-1}$. Colour measurement of the mPLA composites was conducted by using a colour meter (HunterLab, Colourflex EZ) in $L^{*} a^{*} b^{*}$ system.

Water absorption test was performed on the PLA composite filaments by measuring the weight of each specimen at different immersion time following ASTM D 570. The values of the water absorption in percentage were calculated using Equation $2: 9,17$ 


$$
\mathrm{WA}(\%)=100 \times \frac{\mathrm{W}_{\mathrm{t}}-\mathrm{W}_{\mathrm{o}}}{\mathrm{W}_{\mathrm{o}}}
$$

where WA is the water absorption in percent, $\mathrm{W}_{0}$ is the initial weight and $\mathrm{W}_{\mathrm{t}}$ is the weight of specimen at time $t$.
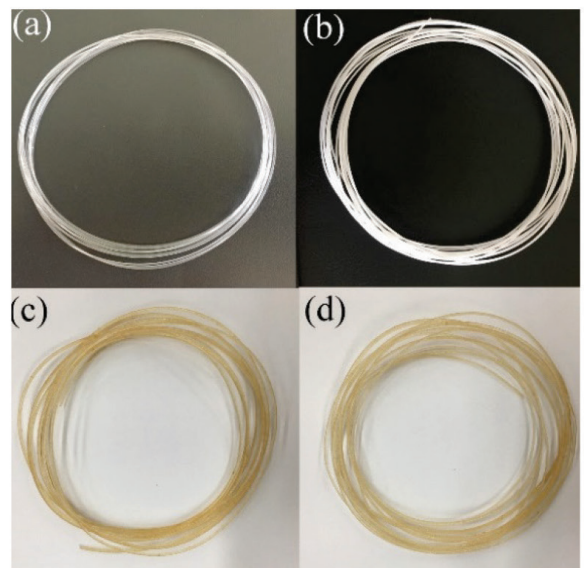

(d)

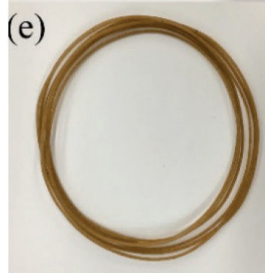

(f)

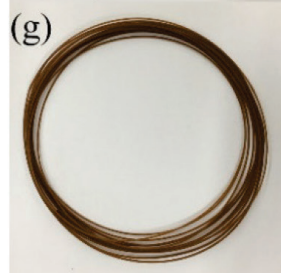

(h)

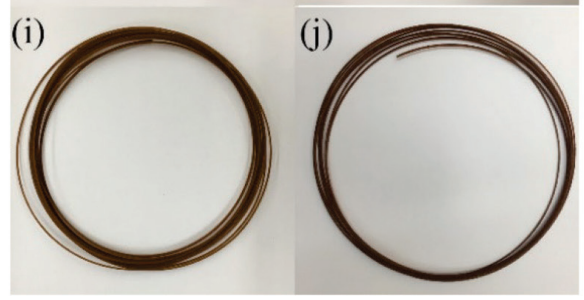

Figure 1: Visual appearance of PLA filaments for: (a) neat PLA, (b) mPLA, (c) mPW74-1, (d) mPW125-1, (e) mPW74-3, (f) mPW125-3, (g) mPW74-5, (h) mPW125-5, (i) mPW74-5S, and (j) mPW125-5S. 


\subsubsection{Printability test}

WPC filaments were printed by using a MakerBot Replicator Z18 3D printer to obtain the final 3D printed products. The filaments were fed into a 3D printer with a nozzle temperature of $200^{\circ} \mathrm{C}$. The layer height was $0.2 \mathrm{~mm}$ and the nozzle diameter of the $3 \mathrm{D}$ printer was $0.4 \mathrm{~mm}$. All the printed formulations were compared with that of commercial PLA filament printed product as well.

\section{RESULTS AND DISCUSSION}

\subsection{Visual Appearance and Colour Measurement of mPLA Composite Filaments}

The visual appearances of the filaments made from neat PLA, mPLA and mPLA/WF with and without silane coupling agent are shown in Figure 1. Their corresponding colour fading values in $L^{*} a^{*} b^{*}$ system are listed in Table 3. Maximum $L^{*}$ value of 100 indicates the perfect reflecting diffuser or whiteness, while $L^{*}$ value of 0 represents black. The $a^{*}$ and $b^{*}$ have no numerical scale limit, positive $a^{*}$ refers to red and the negative value of $a^{*}$ is green. Positive $b^{*}$ value represents yellow and its negative value indicates blue. ${ }^{18}$

In Figure 1, the appearance of the mPLA/WF composites obviously changed with wood content. Colour of the composites faded from white to dark brown as wood content increased. Also, in Table 3 , the $L^{*}$ value decreased with increasing contents of the WF. It reduced from 87.5 observed in the mPLA down to 30.3 and 33.7 for mPLA with $5 \mathrm{wt} \% \mathrm{WF}$ at $74 \mu \mathrm{m}$ and $125 \mu \mathrm{m}$, respectively. For $a^{*}$ and $b^{*}$, the change was minimal. Brown colour of teak WF uniformly distributed all over the surface of the filaments. The visual appearance and the colour measurement value indicated that the WF acted as the pigment reflecting the colour of WF. Previous literatures indicated that the smaller particles of rice hull (less than $106 \mu \mathrm{m}$ ), acted as a pigment, while larger particles were only simply embedded in PVC matrix. ${ }^{18}$

Table 3: Colour measurement of WPC filaments.

\begin{tabular}{lccc}
\hline Formulation code & \multicolumn{1}{c}{$L^{*}$} & $a^{*}$ & $b^{*}$ \\
\hline PLA & Transparent & Transparent & Transparent \\
mPLA & $87.5 \pm 0.21$ & $0.29 \pm 0.04$ & $5.08 \pm 0.48$ \\
mPW74-1 & $39.1 \pm 0.47$ & $1.47 \pm 0.02$ & $9.15 \pm 0.32$ \\
mPW74-3 & $32.9 \pm 0.03$ & $0.22 \pm 0.13$ & $4.84 \pm 0.36$ \\
mPW74-5 & $30.3 \pm 0.20$ & $5.20 \pm 0.18$ & $15.9 \pm 0.22$ \\
\hline
\end{tabular}


Table 3: (continued)

\begin{tabular}{lccc}
\hline Formulation code & $L^{*}$ & $a^{*}$ & $b^{*}$ \\
\hline mPW125-1 & $43.6 \pm 0.35$ & $1.02 \pm 0.33$ & $10.1 \pm 0.32$ \\
mPW125-3 & $37.6 \pm 0.16$ & $3.70 \pm 0.38$ & $7.35 \pm 0.90$ \\
mPW125-5 & $33.7 \pm 0.84$ & $4.84 \pm 0.08$ & $12.7 \pm 0.37$ \\
mPW74-5S & $28.2 \pm 0.22$ & $6.71 \pm 0.69$ & $18.0 \pm 0.58$ \\
mPW125-5S & $29.9 \pm 0.46$ & $7.37 \pm 0.52$ & $16.2 \pm 0.80$ \\
\hline
\end{tabular}

\subsection{Melt Flow Index (MFI)}

As shown in Figure 2, the MFI values of the composites prepared from both $74 \mu \mathrm{m}$ and $125 \mu \mathrm{m}$ WF decreased due to the addition of WF at all content. This was mainly due to the poor flow properties induced by WF and the aggregation of WF during the MFI measurement. ${ }^{19}$ With silane, the MFI increased but only minutely. The decrease of the MFI was generally found in the thermoplastic filled with WF such as polypropylene/WF, polyethylene/WF ${ }^{20}$ In this case, the reduction of the MFI provided good processability for the filament extrusion.

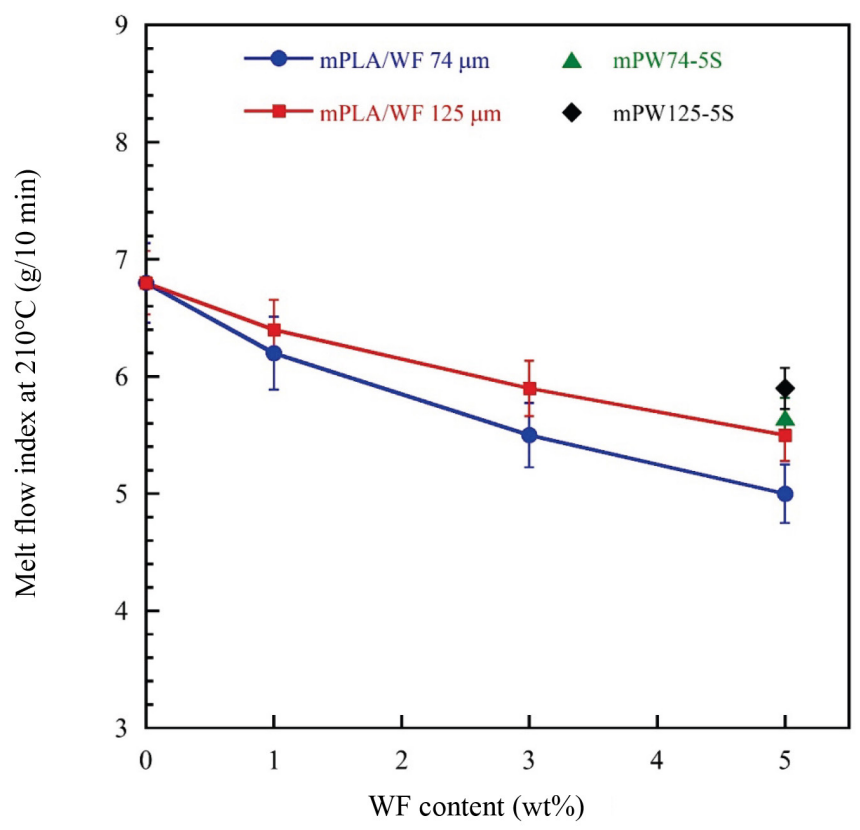

Figure 2: Melt flow index of PLA, mPLA and its composites. 


\subsection{Mechanical Properties}

The tensile strength and elongation at break of mPLA composite filaments are clearly shown in Table 4. mPLA exhibited lower tensile strength than neat PLA by $21 \%$, while the elongation exceeded that of neat PLA by $151 \%$. This is in agreement with our previous works of PLA/CSR and PLA/APA blends..$^{21,22}$ Adding hydrophilic WF to hydrophobic mPLA reduced both the tensile strength and tensile elongation at break. Maximum reduction of the tensile strength by around $23 \%$ was observed at $125 \mu \mathrm{m} \mathrm{WF}$ and $5 \mathrm{wt} \%$, compared to mPLA. For the tensile elongation at break, it did at the identical concentration by around $78 \%$. These were expected due to the fact that adding WF to thermoplastics: (1) reduces the polymeric matrix ductility; (2) limits the matrix-filler stress transfer from the poor interfacial adhesion; and (3) restricts the PLA chain entanglement under tension process. ${ }^{23,24}$ The improvements of both the tensile strength and the elongation at break were evidenced, when modifying WF with $\gamma$-aminopropyl trimethoxy silane. The strength of the silane-treated composites was higher than that of the unmodified ones by around $23 \%$ and $38 \%$ for mPLAW74-5S and mPLAW125-5S, respectively. The elongation at break was found to improve by around 1.5 to 1.7 times. These achievements were mainly due to better interfacial adhesion as presented by FE-SEM micrograph in Figure 3.

Table 4: Tensile properties of PLA composite filaments.

\begin{tabular}{lcc}
\hline & \multicolumn{2}{c}{ PLA composite filaments } \\
\cline { 2 - 3 } Formulation code & $\begin{array}{c}\text { Tensile strength } \\
(\mathrm{MPa})\end{array}$ & $\begin{array}{c}\text { Tensile elongation at break } \\
(\%)\end{array}$ \\
\hline PLA & $68.9 \pm 2.64$ & $6.92 \pm 1.68$ \\
mPLA & $54.1 \pm 3.79$ & $17.4 \pm 5.03$ \\
mPW74-1 & $51.0 \pm 2.68$ & $7.37 \pm 2.07$ \\
mPW74-3 & $46.9 \pm 1.40$ & $5.64 \pm 3.51$ \\
mPW74-5 & $48.5 \pm 2.04$ & $3.78 \pm 5.03$ \\
mPW125-1 & $47.1 \pm 3.41$ & $6.90 \pm 2.65$ \\
mPW125-3 & $43.6 \pm 1.70$ & $4.42 \pm 2.78$ \\
mPW125-5 & $41.5 \pm 2.93$ & $3.91 \pm 4.03$ \\
mPW74-5S & $59.6 \pm 2.66$ & $6.30 \pm 3.40$ \\
mPW125-5S & $57.3 \pm 1.97$ & $5.79 \pm 4.07$ \\
Commercial filament & $52.8 \pm 3.79$ & $8.45 \pm 2.44$ \\
\hline
\end{tabular}




\subsection{Microscopic Observation}

Figure 3 illustrates the microscopic observation of neat PLA, mPLA and MPLA/ WF with and without silane coupling agent. In Figure 3(a), neat PLA fractured with very smooth surface, indicating its brittle nature. Adding CSR and APA to PLA was found to have rougher fracture surface together with the localised plastic deformations, which required much more energy to break the specimen. For the untreated composites, shown in Figures 3(c and e), poor interfacial adhesion was observed with voids between mPLA matrix and WF. Adding the coupling agent to the composites was found to improve the interfacial adhesion between mPLA and WF as evidenced in Figures 3(d and f). This facilitated the filler-matrix stress transfer, which directly increased the tensile strength. This correlation was previously reported, when silane coupling agent was added to thermoplastic/ wood composites. Both the tensile modulus and tensile strength of PP and PLA composites increased with increasing coupling agent content. ${ }^{26,27}$ Bengtsson and Oksman indicated that the flexural strength and elongation at break was dramatically improved in the silane-crosslinked composites. ${ }^{28}$ Moreover, they concluded that the toughness enhancement was mainly caused by improved adhesion between the WF and polymer matrix phases. 

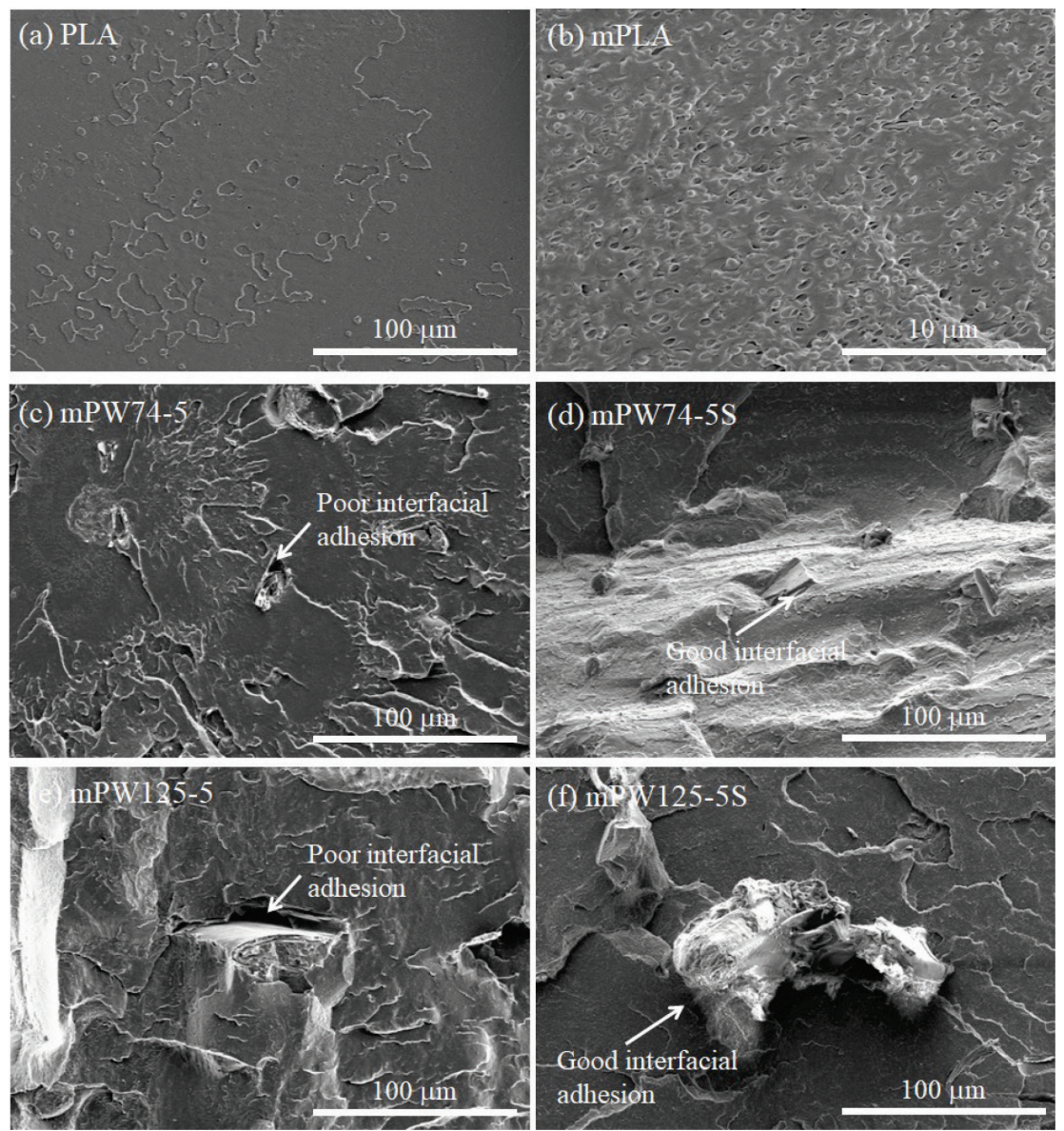

Figure 3: SEM micrograph of PLA, mPLA and mPLA/WF composites.

\subsection{Chemical Bonding Between mPLA, WF and $\gamma$-Aminopropyl Trimethoxy Silane}

The FTIR spectra of the chemical reaction between teak WF and $\gamma$-aminopropyl trimethoxy silane and mPLA graphically presented in Figure 4. Further explanation of the chemical reaction mechanism was also schematically illustrated in Figure 5. Based on the FTIR data, there was no significant difference between the WPC filaments with or without coupling agent. All mPLA composites showed strong peak at around $1744-1748 \mathrm{~cm}^{-1}$, which is related to the $\mathrm{C}=\mathrm{O}$ stretching. However, there was a shift in $\mathrm{C}=\mathrm{O}$ stretching peaks from $1744 \mathrm{~cm}^{-1}$ (without silane) to $1748 \mathrm{~cm}^{-1}$ (with silane). This shift indicated that there were some interactions 
between three components added in the filaments. ${ }^{29}$ However, the spectrum of siloxane ( $\mathrm{Si}-\mathrm{O}-\mathrm{Si}$ ), which was generated from the condensation reaction of silane at $1035 \mathrm{~cm}^{-1}$ and $1068 \mathrm{~cm}^{-1}$ was not observed. These peaks were expected to overlap with the main mPLA spectrum. Further explanation of the chemical reaction of WF, silane coupling agent and mPLA was schematically presented in Figure 5. In the first step, the hydrolysis of $\gamma$-aminopropyl trimethoxy silane reacted with the water molecules and generated the silane with reactive hydroxyl group. Secondly, the filler surface reaction between WF and silane were occurring via $\mathrm{OH}$ groups.

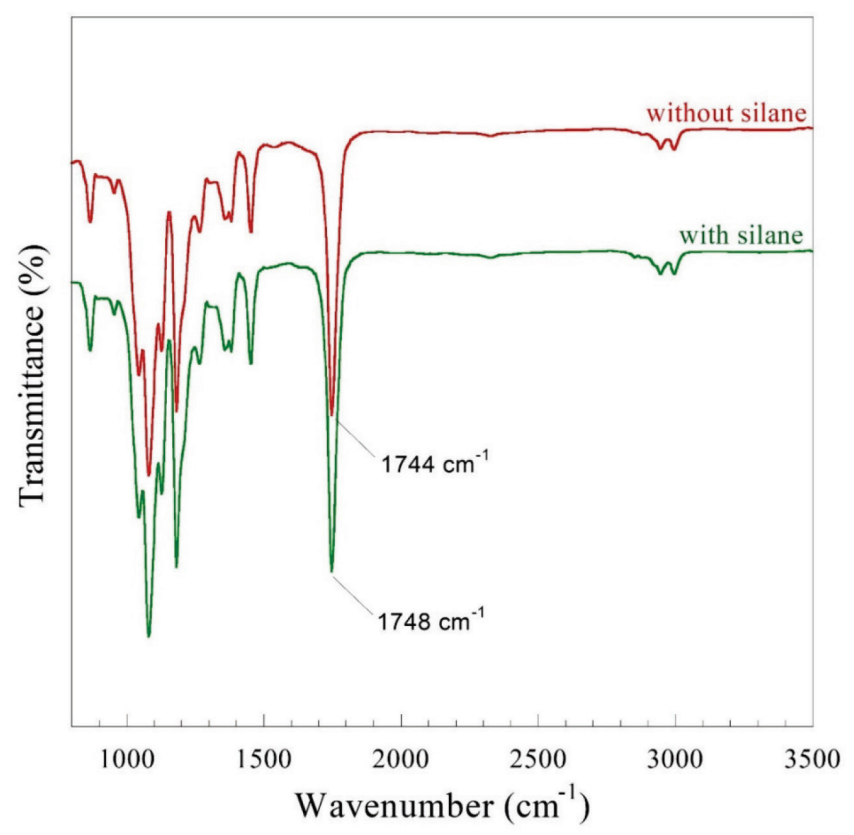

Figure 4: FTIR spectra of mPLA/WF composites with and without $\gamma$-aminopropyl trimethoxy silane coupling agent.

The condensation reactions then took place, forming Si-O-Si linkage..$^{30}$ Lastly, nitrogen bonds were reacted between coupling agent and PLA chains. The identical behaviour was found in PLA/natural fibres composites modified with 3-aminopropyltriethoxy silane, 3-aminopropyltriethoxy silane, ${ }^{32}$-bis-(3-triethoxy silyl propyl) tetrasulfane and $\gamma$-glycidoxypropyl trimethoxy silane. ${ }^{31-33}$ 


\section{Step I Hydrolysis of y-aminopropyl trimethoxysilane}<smiles></smiles>

\section{Step II Filler surface reaction}<smiles>NCCC[Si](O)(O)O[Si](O)(O)CCCN</smiles>

\section{Step III Condensation}<smiles></smiles>

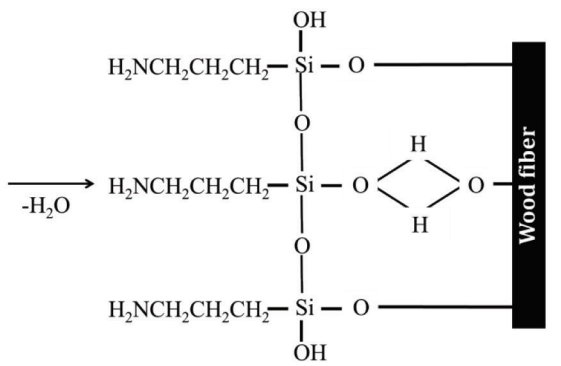

Step IV Reaction with PLA chains

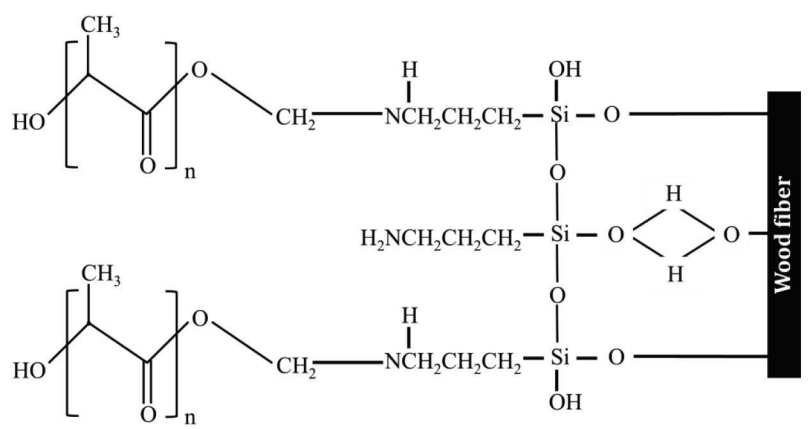

Figure 5: Schematic illustration of the bonding mechanism of $\gamma$-aminopropyl trimethoxy silane coupling to WF and mPLA. 


\subsection{Thermal Properties}

DSC measurements of pure PLA, mPLA, mPLA/WF composites and commercial PLA filament are graphically presented in Figure 6. Their corresponding transition temperatures and the calculated $X_{c}$ values are clearly shown in Table 5. Before melting, the tested samples showed identical peak characteristics. These composed of $T_{g}$ jump at around $50^{\circ} \mathrm{C}-60^{\circ} \mathrm{C}$ and small crystallisation peaks around $100^{\circ} \mathrm{C}-120^{\circ} \mathrm{C}$ depending on the formulation. Single melting endotherm was found in neat PLA, mPLA and mPLA composites with $74 \mu \mathrm{m}$ WF. However, double melting peaks were clearly observed in the other PLA composites and the commercial PLA filaments due to the melt of two different crystal structures. ${ }^{6,34,35}$ Reductions of $T_{g}$ at all formulations indicated that they were capable of crystallising earlier than neat PLA by around $10^{\circ} \mathrm{C}$. Both the $T_{c}$ and $T_{m}$ fluctuated in a range of $5^{\circ} \mathrm{C}-10^{\circ} \mathrm{C}$, while the $X_{c}$ reduced to less than $2 \%$. This was possibly due to the crystallisation hindrance of WF in mPLA and because of this, the composites had more amorphous region. ${ }^{15}$
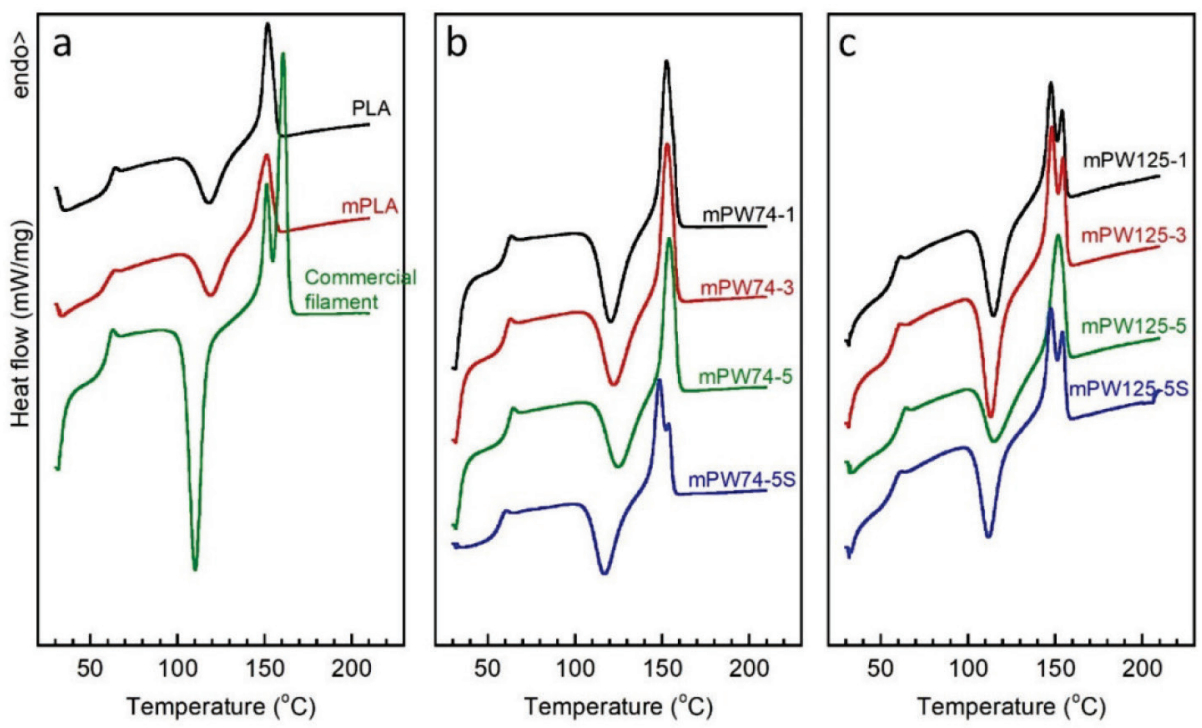

Figure 6: DSC thermograms of PLA, mPLA and mPLA composites with and without silane coupling agent. 
Table 5: Transition temperatures and degree of crystallinity of WPC filaments.

\begin{tabular}{lllll}
\hline Formulation code & $\mathrm{T}_{\mathrm{g}}\left({ }^{\circ} \mathrm{C}\right)$ & $\mathrm{T}_{\mathrm{c}}\left({ }^{\circ} \mathrm{C}\right)$ & $\mathrm{T}_{\mathrm{m} 1} / \mathrm{T}_{\mathrm{m} 2}\left({ }^{\circ} \mathrm{C}\right)$ & $\mathrm{X}_{\mathrm{c}}(\%)$ \\
\hline PLA & 62.55 & 116.7 & $150.3 /-$ & 5.85 \\
mPLA & 61.83 & 117.1 & $151.2 /-$ & 3.69 \\
mPW74-1 & 60.91 & 122.6 & $152.5 /-$ & 1.14 \\
mPW74-3 & 60.84 & 124.9 & $153.6 /-$ & 1.75 \\
mPW74-5 & 62.19 & 125.6 & $154.3 /-$ & 1.22 \\
mPW125-1 & 58.87 & 118.3 & $146.4 / 155.9$ & 2.47 \\
mPW125-3 & 57.31 & 110.5 & $149.5 / 155.5$ & 1.96 \\
mPW125-5 & 59.28 & 112.8 & $152.8 /-$ & 3.98 \\
mPW74-5S & 58.95 & 113.1 & $149.2 / 153.5$ & 1.03 \\
mPW125-5S & 59.42 & 116.2 & $148.7 / 153.4$ & 0.28 \\
Commercial filament & 60.52 & 109.8 & $151.7 / 160.5$ & N/A* \\
\hline
\end{tabular}

*The $X_{P L A}$ was unknown.

\subsection{Water Absorption}

Figure 7 shows the water absorption of the neat PLA, mPLA and mPLA/WF composites at the soaking time of 90 days. Neat PLA absorbed water by around $1.8 \%$, while mPLA did at $1.2 \%$. Further addition of WF was found to have higher water uptake, due to its hydrophilicity. ${ }^{12}$ However, there was no significant difference between the sizes of the milled WF studied. With silane coupling agent, the water absorption evidently decreased by around $38 \%$ and $32 \%$ for $\mathrm{mPW} 74-5 \mathrm{~S}$ and $\mathrm{mPW} 125-5 \mathrm{~S}$, respectively. These reductions were mainly due to the improvement of the interfacial adhesion between mPLA matrix and WF as illustrated in Figure 3. ${ }^{8}$ 


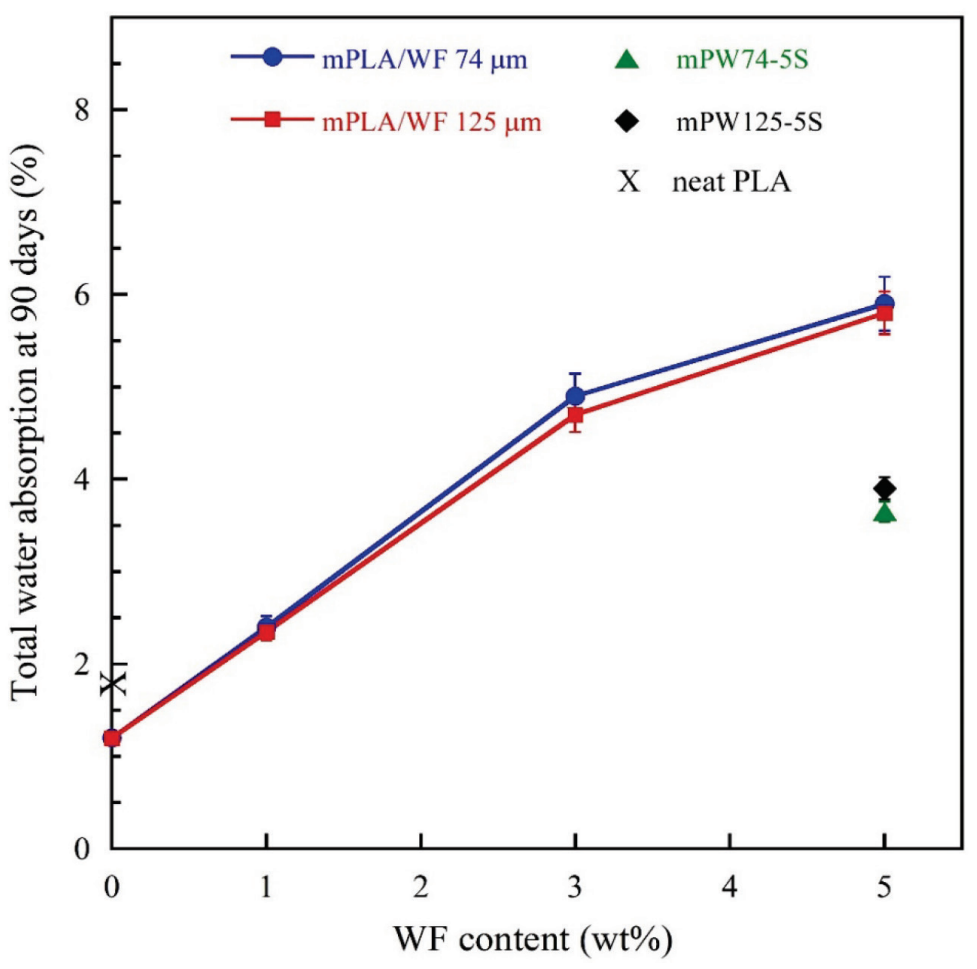

Figure 7: Total water absorption at 90 days immersion.

\subsection{D Printing Test}

To confirm the printability of the composites, the filaments were printed and compared with those of commercial one. However, the filaments were successfully printed only for the mPLA with $74 \mu \mathrm{m}$ WF. For $125 \mu \mathrm{m}$, the printer nozzle was clogged up with the agglomerated WF. Figure 8 illustrates the 3D printed chains of the commercial PLA filament, mPW74-5 and mPW74-5S filaments. The composites with WF made the product like a wooden material when compared to the commercial PLA filament. However, there was no significant difference among the products printed from commercial and untreated and silane-treated $\mathrm{mPLA} /$ wood filaments. This indicated that all the formulations of $74 \mu \mathrm{m} \mathrm{WF}$ could be used as 3D filaments for FDM process. 


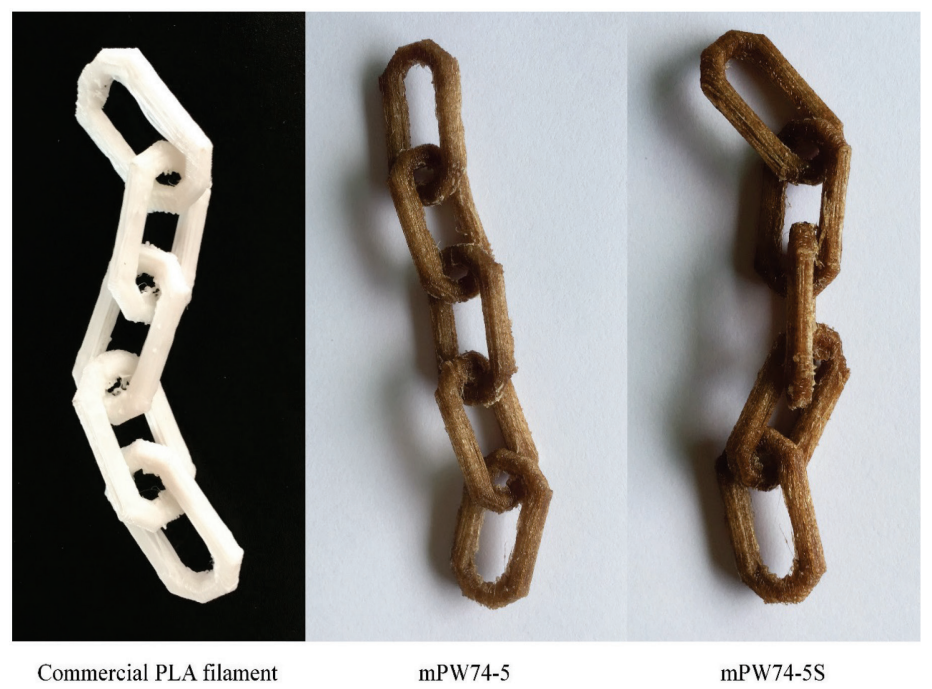

Figure 8: 3D printed products with and without silane coupling agent compared with commercial PLA filament.

\section{CONCLUSION}

The 3D printing filaments of the neat PLA, mPLA, mPLA with $74 \mu \mathrm{m}$ and $125 \mu \mathrm{m}$ WF were successfully produced in the current research. However, the filaments were successfully printed only for the mPLA with $74 \mu \mathrm{m}$ WF. Adding WF to mPLA gave the $3 \mathrm{D}$ printed products with the wood-like appearance. DSC measurement indicated that the composites had more amorphous region due to the crystallisation hindrance of WF in mPLA. The addition of WF was found to have higher water uptake but it decreased with the silane compatibilisation. SEM result also confirmed the improvement of the interfacial bonding between mPLA and WF. This facilitated better fibre-matrix stress transfer and improved the mechanical strength of the composites.

\section{ACKNOWLEDGEMENTS}

The authors would like to acknowledge the research grant supported by Srinakharinwirot University, Thailand (contract no. 006/2561). Thanks are extended to Mr. Kittisak Promsukm, Ms. Jutathip Jaowanna and Mr. Pramond Ruamrattanasin for the preliminary study of this research. 


\section{REFERENCES}

1. Stansbury, J. W. \& Idacavage, M. J. (2016). 3D printing with polymers: Challenges among expanding options and opportunities. Dent. Mater., 32(1), 54-64, https:// doi.org/10.1016/j.dental.2015.09.018.

2. Wang, X. et al. (2017). 3D printing of polymer matrix composites: A review and prospective. Compos. B Eng., 110, 442-458, https://doi.org/10.1016/j. compositesb.2016.11.034.

3. Tao, Y. et al. (2017). Development and application of wood flour-filled polylactic acid composite filament for 3D printing. Mater., 10(4), 339, https://doi.org/10.3390/ ma10040339.

4. Masood, S. H. \& Song, W. Q. (2004). Development of new metal/polymer materials for rapid tooling using fused deposition modelling. Mater. Des., 25(7), 587-594, https://doi.org/10.1016/j.matdes.2004.02.009.

5. Tran, P. et al. (2017). Bimaterial 3D printing and numerical analysis of bio-inspired composite structures under in-plane and transverse loadings. Compos. B Eng., 108, 210-223, https://doi.org/10.1016/j.compositesb.2016.09.083.

6. Petchwattana, N. et al. (2018). Crystallization behavior and transparency of poly(lactic acid) nucleated with dimethylbenzylidene sorbitol. Plast. Rubber Compos., 48(4), 147-155, https://doi.org/10.1080/14658011.2018.1447338.

7. Xia, X. L. et al. (2014). Degradation behaviors, thermostability and mechanical properties of poly (ethylene terephthalate)/polylactic acid blends. J. Cent. South. Univ., 21(5), 1725-1732, https://doi.org/10.1007/s11771-014-2116-z.

8. Petchwattana, N. \& Sanetuntikul, J. (2018). Static and dynamic mechanical properties of poly(vinyl chloride) and waste rice husk ash composites compatibilized with $\gamma$-aminopropyltrimethoxysilane. Silicon, 10(2), 287-292, https://doi.org/10.1007/s12633-016-9440-x.

9. Petchwattana, N. et al. (2017). Wood plastic composites prepared from biodegradable poly(butylene succinate) and Burma padauk sawdust (Pterocarpus macrocarpus): Water absorption kinetics and sunlight exposure investigations. J. Bionic Eng., 14(4), 781-790, https://doi.org/10.1016/S1672-6529(16)60443-2.

10. Csikós, Á. et al. (2015). Modification of interfacial adhesion with a functionalized polymer in PLA/wood composites. Eur. Polym. J., 68, 592-600, https://doi. org/10.1016/j.eurpolymj.2015.03.03.

11. Asim, M. et al. (2018). The effect of silane treated fibre loading on mechanical properties of pineapple leaf/kenaf fibre filler phenolic composites. J. Polym. Environ., 26(4), 1520-1527, https://doi.org/10.1007/s10924-017-1060-z.

12. Petchwattana, N., Covavisaruch, S. \& Chanakul, S. (2012). Mechanical properties, thermal degradation and natural weathering of high density polyethylene/rice hull composites compatibilized with maleic anhydride grafted polyethylene. J. Polym. Res., 19(7), 9921, https://doi.org/10.1007/s10965-012-9921-6.

13. Hernández-Alamilla, M. \& Valadez-Gonzalez, A. (2016). The effect of two commercial melt strength enhancer additives on the thermal, rheological and morphological properties of polylactide. J. Polym. Eng., 36(1), 31-41, https://doi. org/10.1515/polyeng-2014-0322. 
14. Feng, Y. et al. (2018). The crystallization behavior of poly(lactic acid) with different types of nucleating agents. Int. J. Biol. Macromol., 106, 955-962, https:// doi.org/10.1016/j.ijbiomac.2017.08.095.

15. Petchwattana, N., Sanetuntikul, J. \& Narupai, B. (2018). Plasticization of biodegradable poly (lactic acid) by different triglyceride molecular sizes: A comparative study with glycerol. J. Polym. Environ., 26(3), 1160-1168, https:// doi.org/10.1007/s10924-017-1012-7.

16. Kracalik, M. (2017). Effect of organoclay chemistry and morphology on properties of poly(lactic acid) nanocomposites. Plast. Rubber Compos., 46(9), 389-395, https://doi.org/10.1080/14658011.2017.1373489.

17. Ghani, S. A. et al. (2016). The effect of the chemical modification of wood fibre using salicylic acid and ethanol on the properties of recycled high density polyethylene/wood fibre composites. J. Phys. Sci., 27(1), 1-14.

18. Petchwattana, N. \& Covavisaruch, S. (2013). Effects of rice hull particle size and content on the mechanical properties and visual appearance of wood plastic composites prepared from poly(vinyl chloride). J. Bionic Eng., 10(1), 110-117, https://doi.org/10.1016/S1672-6529(13)60205-X.

19. Li, H., Law, S. \& Sain, M. (2004). Process rheology and mechanical property correlationship of wood flour-polypropylene composites. J. Reinf. Plast. Compos., 23(11), 1153-1156, https://doi.org/10.1177/0731684404035416.

20. Li, H., Law, S. \& Sain, M. (2004). Process rheology and mechanical property correlationship of wood flour-polypropylene composites. J. Reinf. Plast. Compos., 23(11), 1153-1158, https://doi.org/10.1177/0731684404035416.

21. Petchwattana, N. \& Covavisaruch, S. (2014). Mechanical and morphological properties of wood plastic biocomposites prepared from toughened poly(lactic acid) and rubber wood sawdust (Hevea brasiliensis). J. Bionic Eng., 11(4), 630637, https://doi.org/10.1016/S1672-6529(14)60074-3.

22. Petchwattana, N. et al. (2017). Modification of poly(lactic acid) by blending with poly(methyl methacrylate-co-ethyl acrylate) for extrusion blow molding application. J. Eng. Sci. Technol., 12(10), 2766-2777.

23. Yussuf, A. A., Massoumi, I. \& Hassan, A. (2010). Comparison of polylactic acid/ kenaf and polylactic acid/rise husk composites: The influence of the natural fibers on the mechanical, thermal and biodegradability properties. J. Polym. Environ., 18(3), 422-429, https://doi.org/10.1007/s10924-010-0185-0.

24. Savetlana, S. et al. (2018). Properties of nylon-6-based composite reinforced with coconut shell particles and empty fruit bunch fibres. Plast. Rubber Compos., (47)2, 77-86, https://doi.org/10.1080/14658011.2017.1418711.

25. Kuo, P. Y. et al. (2009). Effects of material compositions on the mechanical properties of wood-plastic composites manufactured by injection molding. Mater. Design, 30(9), 3489-3496, https://doi.org/10.1016/j.matdes. 2009.03.012.

26. Lv, S. et al. (2015). Silane modified wood flour blended with poly(lactic acid) and its effects on composite performance. BioResour., 10(3), 5426-5439, https://doi. org/10.15376/biores10.3.5426-5439.

27. Rimdusit, S. et al. (2011). Highly filled polypropylene rubber wood flour composites. Eng. J., 15(2), 17-30, https://doi.org/10.4186/ej.2011.15.2.17. 
28. Bengtsson, M. \& Oksman, K. (2006). The use of silane technology in crosslinking polyethylene/wood flour composites. Compos. A-Appl. S, 37(5), 752-765, https:// doi.org/10.1016/j.compositesa.2005.06.014.

29. Eng, C. C. et al. (2014). Impact strength and flexural properties enhancement of methacrylate Silane treated oil palm mesocarp fiber reinforced biodegradable hybrid composite. Sci. World J., 2014, 213180, https://doi.org/10.1155/2014/213180.

30. Sis, A. L. M., Ibrahim, N. A.\& Yunus, W. M. Z. W. (2013). Effect of (3-aminopropyl) trimethoxysilane on mechanical properties of PLA/PBAT blend reinforced kenaf fiber. Iran. Polym. J., 22(2), 101-108, https://doi.org/10.1007/s13726-012-0108-0.

31. Chun, K. S., Husseinsyah, S. \& Osman, H. (2012). Mechanical and thermal properties of coconut shell powder filled polylactic acid biocomposites: Effects of the filler content and silane coupling agent. J. Polym. Res., 19, 9859, https://doi. org/10.1007/s10965-012-9859-8.

32. Jandas, P. J., Mohanty, S. \& Nayak, S. K. (2012). Renewable resource-based biocomposites of various surface treated banana fiber and poly lactic acid: Characterization and biodegradability. J. Polym. Environ., 20(2), 583-595, https:// doi.org/10.1007/s10924-012-0415-8.

33. Tran, T. P. T., Bénézet, J. C. \& Bergeret, A. (2014). Rice and Einkorn wheat husks reinforced poly(lactic acid)(PLA) biocomposites: Effects of alkaline and silane surface treatments of husks. Ind. Crop. Prod., 58, 111-124, https://doi. org/10.1016/j.indcrop. 2014.04.012.

34. Nagarajan, V. et al. (2015). Overcoming the fundamental challenges in improving the impact strength and crystallinity of PLA biocomposites: Influence of nucleating agent and mold temperature. ACS Appl. Mater. Interf., 7(21), 11203, https://doi. org/10.1021/acsami.5b01145.

35. Petchwattana, N. \& Narupai, B. (2019). Synergistic effect of talc and titanium dioxide on poly(lactic acid) crystallization: An investigation on the injection molding cycle time reduction. J. Polym. Environ., 27(4), 837-846, https://doi. org/10.1007/s10924-019-01396-0. 